\title{
Heterochromatin distribution and localization of nucleolar organizing regions in the $2 n=52$ cytotypes of Nannospalax xanthodon and N. ehrenbergi from Turkey
}

\author{
Atilla Arslan ${ }^{1}$ and Jan Zima ${ }^{2 *}$
}

\begin{abstract}
Background: The blind mole rats (Spalacinae) are fossorial rodents exhibiting exceptionally extensive variation in the karyotype. The taxonomy of this group is not definitively resolved, and the species discrimination is often not clear, even with the use of chromosomal analyses.

Results: We have studied the karyotype of three populations of blind mole rats (Spalacinae) from Anatolia classified tentatively as Nannospalax xanthodon (Bolu and Içel provinces) and Nannospalax ehrenbergi (Gaziantep province). C-banding and AgNOR staining were used in the cytogenetic analysis. In all populations, the karyotype comprised 52 chromosomes including 8 to 10 bi-armed and 17 to 15 acrocentric autosomal pairs. The centromeric position varied in the sex chromosomes between the populations. The C-positive centromeric bands occurred in most of the bi-armed autosomes and the sex chromosomes and in some of the acrocentric autosomes. The nucleolar organizer regions were localized in three (N. xanthodon) or five (N. ehrenbergi) autosomal pairs.
\end{abstract}

Conclusions: It is difficult to find particular chromosomal differences between the studied populations which could enable unequivocal species identification. This finding emphasizes the need of taxonomic revision of the species structure within the Nannospalax genus.

Keywords: Mole rats; Species; Systematics; Karyotypes

\section{Background}

The blind mole rats (Spalacinae; see Musser and Carleton 2005) are a group of fossorial rodents exhibiting exceptionally extensive variation in the karyotype (Kryštufek and Vohralík 2009, Arslan and Zima 2014 for review). This variation has been recorded within and between populations as well as within and between species. The species composition of Spalacinae, however, has not been yet definitively settled. Chişamera et al. (2014) demonstrated that the division of the extant species into two distinct genera, Spalax and Nannospalax, is justified and congruent with the pattern of phylogenetic divergence. The exceptional karyotype diversification is apparently confined

\footnotetext{
* Correspondence: jzima@brno.cas.cz

${ }^{2}$ Institute of Vertebrate Biology, Academy of Sciences of the Czech Republic, Kvetna 8, 60365 Brno, CZ, Czech Republic

Full list of author information is available at the end of the article
}

to the genus Nannospalax which includes, in a traditional view, three nearly parapatric species, Nannospalax leucodon, Nannospalax xanthodon, and Nannospalax ehrenbergi (Kryštufek and Vohralík 2009). In respect of the remarkable chromosomal variation, various authors have proposed to recognize additional species, and the descriptions were mainly based on characteristic chromosomal features (Nevo et al. 2001, Coşkun 2004, Kankılıç and Gürpinar 2014). The taxonomy of the Nannospalax genus is thus not definitively resolved, and the species discrimination is often not clear, even with the use of chromosomal analyses.

In the present study, we aim to improve karyotypic characteristics revealed by C-banding and AgNOR staining in several cytotypes with 52 chromosomes included either in $N$. xanthodon or N. ehrenbergi. In Turkey, populations possessing 52 chromosomes were reported 
from northern Anatolia (e.g., Sözen 2004, Sözen et al. 2013) and from south-eastern Anatolia (Sözen and Kıvanç 1998, Nevo et al. 1995, Ivanitskaya et al. 1997, Coşkun et al. 2006, 2010). The former populations were recognized as $N$. xanthodon (formerly also as leucodon or nehringi), whereas those from south-eastern Anatolia, the populations with 52 chromosomes have commonly been classified within $N$. ehrenbergi. This cytotype was reported also from Iraq (Coşkun et al. 2012), and populations with $2 n=52$ are known from Israel and were named here Spalax galili by Nevo et al. (2001). We attempt to investigate if the specific distinction among individual populations from Anatolia is reflected also in their karyotypic differentiation inferred from the C-banding and AgNOR staining pattern. To answer this question, we compare the results with other reports of chromosomal banding patterns found in Turkish populations of Nannospalax (Ivanitskaya et al. 1997, Ivanitskaya et al. 2008, Arslan and Bölükbaş 2010, Arslan et al. 2011a,b, Arslan and Zima 2013, Arslan et al. 2013, 2014).

\section{Methods}

Cytogenetic analyses were performed in six specimens of $N$. xanthodon and N. ehrenbergi from three Turkish populations. The specimens were caught with the use of a metal pipe-type trap (Arslan 2013), and this trapping method enabled to obtain living individuals without any injury. The study was done, and the specimens were obtained with the permission of Republic of Turkey, Ministry of Forest and Water Works (permit no. 89291). Standard voucher specimens (skins and skulls) are deposited at Selçuk University, Biology Department, Faculty of Science, Konya, Turkey. The number of specimens analyzed and location of the collection sites of mole rats are shown in Figure 1 and Table 1. The species discrimination was based on geographic distribution of the studied populations. The available maps of the distribution ranges of blind mole rats in Turkey (Bukhnikashvili et al. 2008, Schlitter et al. 2008, Kryštufek and Vohralík 2009) suggest that the populations from Bolu and Içel (Mersin) are situated within the range of N. xanthodon, whereas the population from Gaziantep within the range of $N$. ehrenbergi.

Karyotype preparations were obtained in the field from the bone marrow after colchicine treatment (Ford and Hamerton 1956). Air-dried preparations were stained conventionally by Giemsa. Constitutive heterochromatin and nucleolus organizer regions (NORs) were detected by the techniques of C-banding (Sumner 1972) and silver staining of nucleolar organizer regions (Howell and Black 1980), respectively. From each specimen, 10 to 20 slides were prepared, and at least 20 well-spread metaphase plates were analyzed. The system of classification of chromosomes according to the centromere position was adopted after Hsu and Benirschke (1967-1977), and the bi-armed (metacentric M, submetacentric SM, subtelocentric ST) and uni-armed (acrocentric A) chromosomes were distinguished. The fundamental number of autosomal arms (NFa) and the number of all chromosomal arms in the female complement (NF) were calculated.

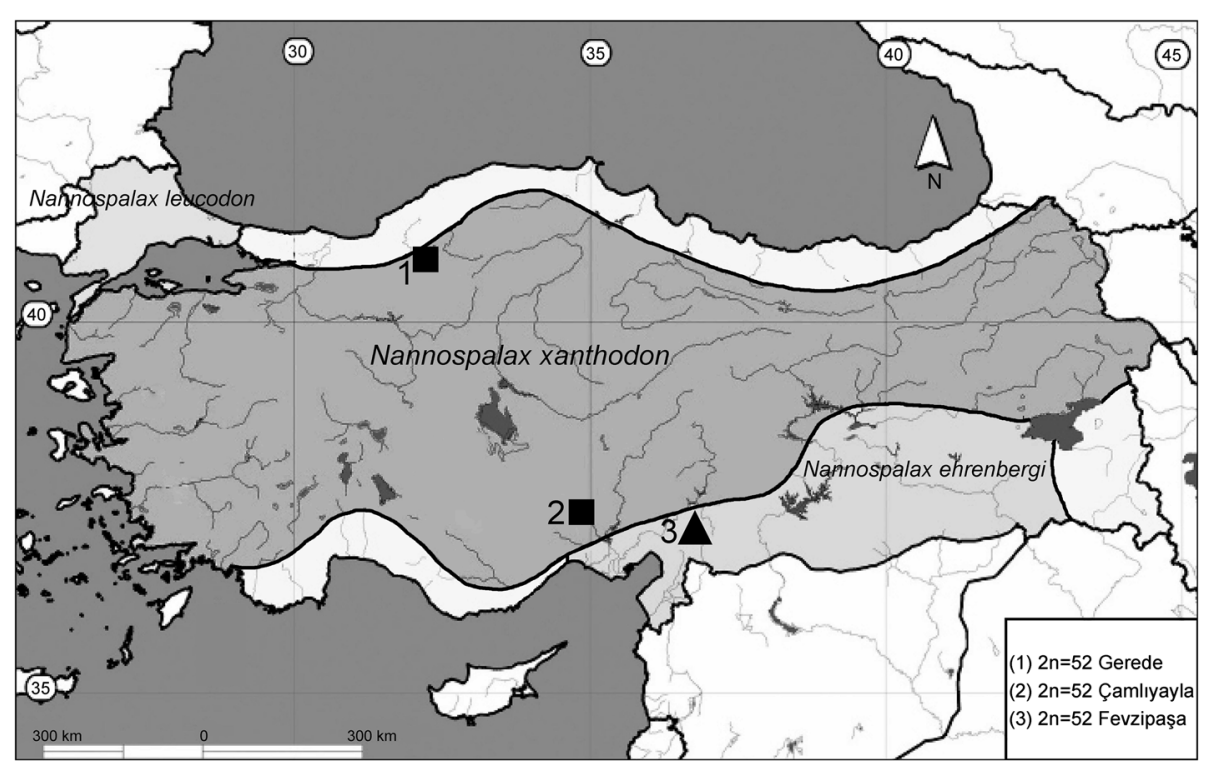

Figure 1 Collecting sites of Nannospalax xanthodon (black square) and $N$. ehrenbergi (black triangle) in Turkey. The numbering of sampling localities corresponds to data in Table 1. The approximate ranges of both species are indicated after Kryštufek and Vohralík (2009). 
Table 1 Studied samples in Turkey and the basic characteristics of the examined specimens

\begin{tabular}{|c|c|c|c|c|c|c|c|c|c|c|}
\hline \multirow[t]{2}{*}{ No. } & \multirow[t]{2}{*}{ Species } & \multirow[t]{2}{*}{ Locality/province } & \multirow[t]{2}{*}{ Latitude/longitude } & \multicolumn{2}{|c|}{ No. of specimens } & \multirow[t]{2}{*}{$2 n$} & \multirow[t]{2}{*}{$\mathrm{NF}$} & \multirow[t]{2}{*}{$\mathrm{NFa}$} & \multirow[t]{2}{*}{$\mathrm{x}$} & \multirow[t]{2}{*}{$\mathrm{Y}$} \\
\hline & & & & Male & Female & & & & & \\
\hline 1 & N. xanthodon & Gerede/Bolu & $40^{\circ} 46^{\prime} \mathrm{N}, 32^{\circ} 13^{\prime} \mathrm{E}$ & 2 & - & 52 & 70 & 66 & ST & $\mathrm{A} / \mathrm{M}$ \\
\hline 2 & N. xanthodon & Çamlıyayla/i̇çel & $37^{\circ} 10^{\prime} \mathrm{N}, 34^{\circ} 36^{\prime} \mathrm{E}$ & 1 & 1 & 52 & 72 & 68 & SM & $A$ \\
\hline 3 & N. ehrenbergi & Fevzipaşa/Gaziantep & $37^{\circ} 05^{\prime} \mathrm{N}, 36^{\circ} 38^{\prime} \mathrm{E}$ & 1 & 1 & 52 & 74 & 70 & SM & $A$ \\
\hline
\end{tabular}

The numbering of the sampling sites corresponds to data in Figure 1.

\section{Results}

Bolu province, Gerede population

The karyotype of the two males consisted of 52 chromosomes including a large subtelocentric (no. 1), two metacentric (nos. 2, 8), three submetacentric (nos. 3, 5, 7), two medium-sized subtelocentric (nos. 4, 6), and 17 acrocentric autosomal pairs of gradually diminishing size (nos. 9 to 25) $(\mathrm{NFa}=66)$. The $\mathrm{X}$ chromosome was a medium-sized subtelocentric; the $\mathrm{Y}$ was a small metacentric $(\mathrm{NF}=70)$ (Figure 2.1). The dark centromeric C-bands were observed in five biarmed ( 1 to 5 ) and some of acrocentric autosomes (nos. 10, 13, 14, 16). In the acrocentric autosomal pairs 13 and 14, the position of the dark C-bands appeared interstitial, not directly involving the centromeric region. $\mathrm{C}$-heterochromatic short arms were not recorded in any autosomal pair in the complements. The sex chromosomes had distinct pericentromeric C-positive bands (Figure 3.1). The NORs were observed in the telomeric regions of the short arms of the autosomes 4,6 , and 8 , with an occasionally heterozygous signal on the autosome 8 (Figure 4.1).

\section{İçel province, Çamlıyayla population}

The karyotype of a male and a female consisted of 52 chromosomes including a large submetacentric and a large subtelocentric pair (no. 1, 2), two metacentric pairs (nos. 3, 4), five submetacentric or subtelocentric pairs of medium size (nos. 5 to 9), and 16 acrocentric autosomal pairs of gradually diminishing size (nos. 10 to 25) $(\mathrm{NFa}=68)$. The $\mathrm{X}$ chromosome was a large submetacentric

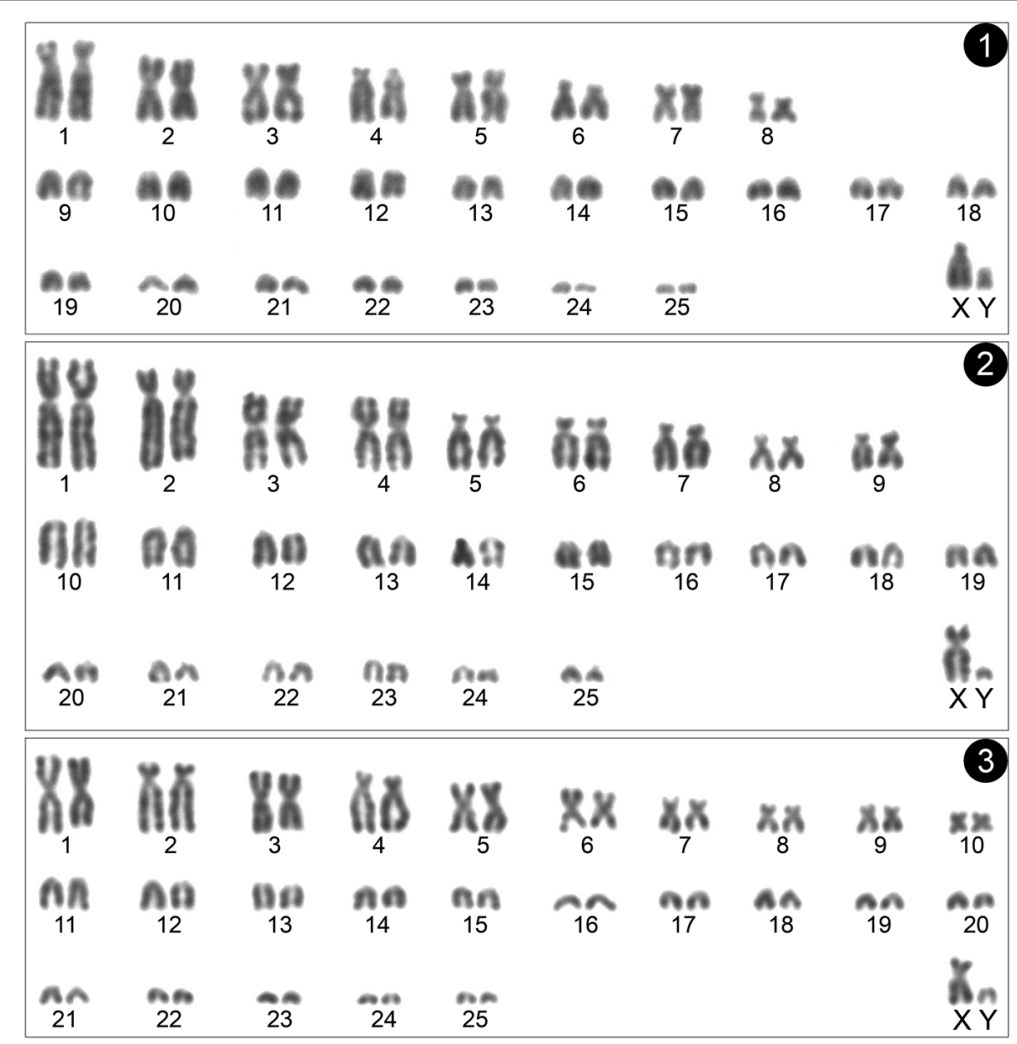

Figure 2 Standard karyotypes of specimens of Nannospalax xanthodon from Gerede (1) and Çamliyayla (2) and N. ehrenbergi from Fevzipaşa (3). 


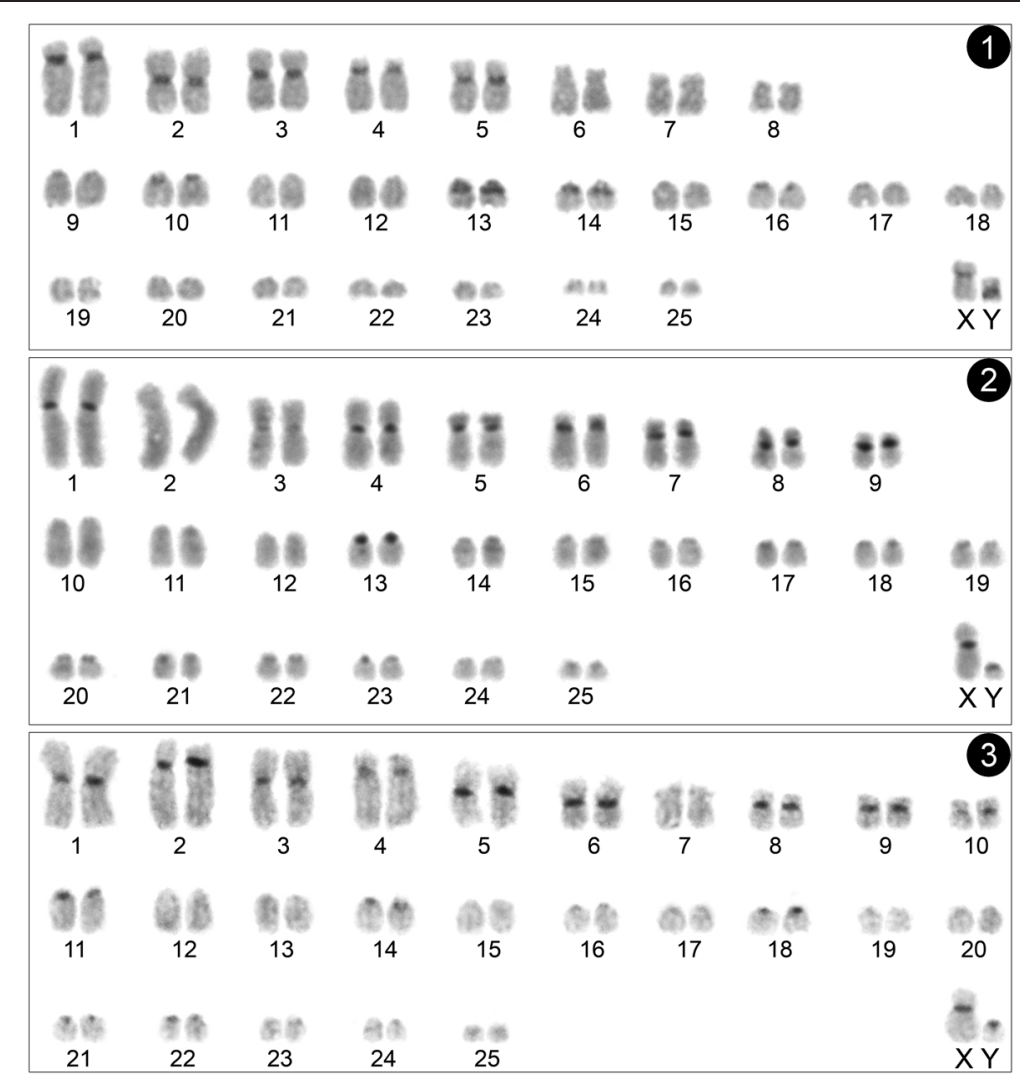

Figure 3 C-banded karyotypes of specimens of Nannospalax xanthodon from Gerede (1) and Çamlıyayla (2) and N. ehrenbergi from Fevzipaşa (3).

and the $\mathrm{Y}$ chromosome was a small acrocentric $(\mathrm{NF}=72)$ (Figure 2.2). The dark C-bands were observed in the centromeric areas of all the bi-armed autosomes except of the pairs 2 and 3 and in the acrocentric autosome 13. Tiny positive centromeric bands were apparent also in some other acrocentric pairs. The sex chromosomes had a centromeric C-positive area (Figure 3.2). The NORs were observed in the telomeric regions of the short arms of the autosomes 5, 6, and 8 (Figure 4.2).

\section{Gaziantep province, Fevzipaşa population}

The karyotype of a male and a female consisted of 52 chromosomes including four metacentric pairs (nos. 1, $3,5,10)$, six submetacentric or subtelocentric pairs (nos. 2, 4, 6 to 9), and 15 acrocentric autosomal pairs of gradually diminishing size (nos. 11 to 25$)(\mathrm{NFa}=70)$. The $\mathrm{X}$ chromosome was a medium-sized submetacentric, the $\mathrm{Y}$ a small acrocentric $(\mathrm{NF}=74)$ (Figure 2.3). The dark C-bands were observed in the centromeric areas of all the bi-armed autosomes except of the pair 7 and in three acrocentric autosomes (nos. 11, 14, 18). Tiny positive centromeric bands were apparent also in some other acrocentric pairs (nos. 21, 22). The sex chromosomes had distinct centromeric C-positive bands (Figure 3.3). The
NORs were observed in the telomeric regions of the short arms of the bi-armed autosomes 2, 4, 7, and 8. In the pairs 4 and 7 , the positive signal was observed in only one homologue of the pair in some cells. The NOR was detected also in the acrocentric chromosome 15 (Figure 4.3).

\section{Discussion}

The comparison of chromosomal complements between the three studied populations shows great similarities between them. All the karyotypes contain 52 chromosomes with 8 to 10 bi-armed and 17 to 15 acrocentric autosomes. The sex chromosomes reveal variation in the centromeric position but their size seems similar in all individuals. The homology of the bi-armed autosomes between individual complements seems uncertain, and it is even improbable in some cases (e.g., in the two largest autosomal pairs). Unfortunately, we cannot evaluate the nature of homology and possible rearrangements involved in presumed diversification without the use of appropriate banding techniques. The pattern of the distribution of C-positive heterochromatin regions is also similar in the three karyotypes compared, with dark centromeric bands occurring in most of the bi-armed 


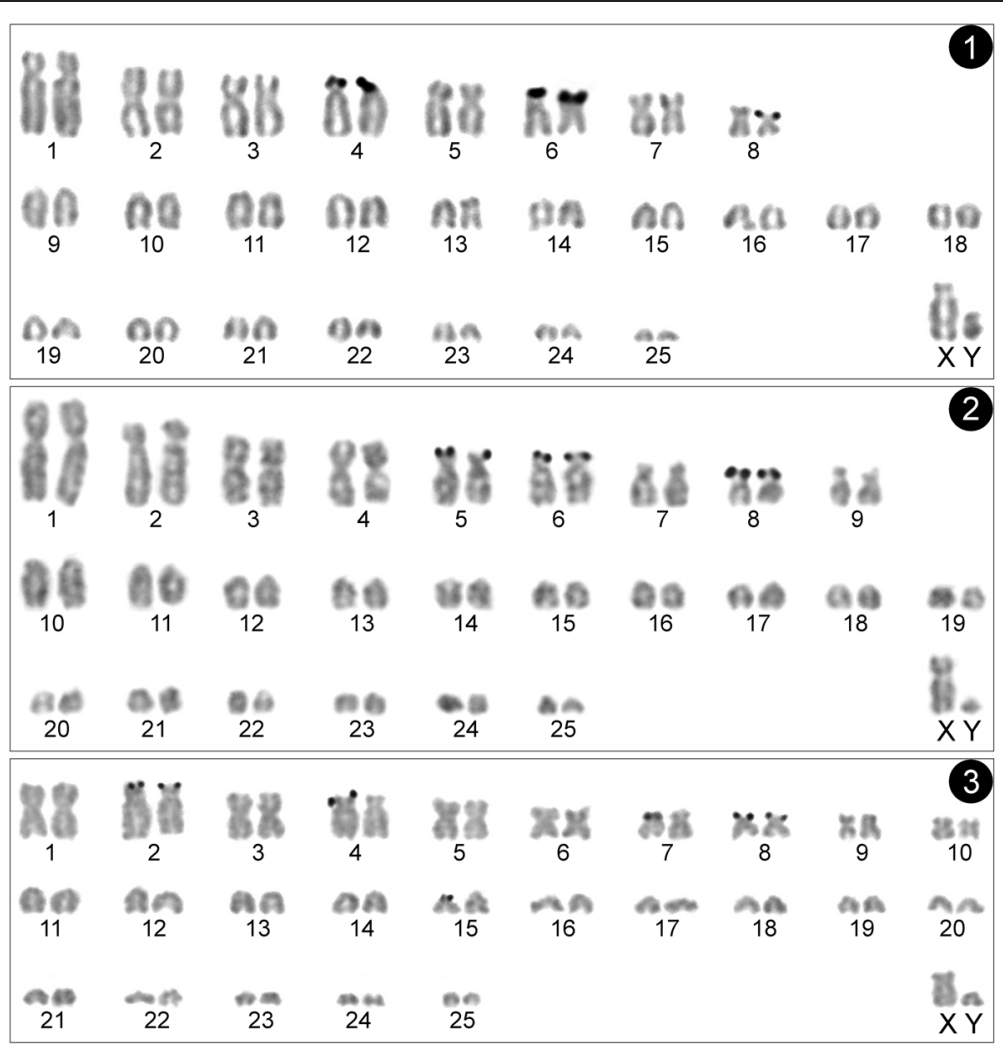

Figure 4 Silver-stained karyotypes of specimens of Nannospalax xanthodon from Gerede (1) and Çamlıyayla (2) and N. ehrenbergi from Fevzipaşa (3).

autosomes and the sex chromosomes and in some of the acrocentric autosomes.

In the karyotype with 52 chromosomes of blind mole rat populations from northern Anatolia, 8 to 9 bi-armed autosomal pairs were distinguished (Sözen 2004, Sözen et al. 2013), whereas in the karyotype of populations from south-eastern Anatolia, 11 or 13 bi-armed autosomal pairs were found (Yüksel 1984, Ivanitskaya et al. 1997, Coşkun et al. 2006, 2010). Ivanitskaya et al. (1997) found in this cytotype pericentromeric blocks of Cheterochromatin in one metacentric autosomal pair and one subtelocentric pair, and distinct dark C-bands were observed also in the pericentromeric area of all acrocentric autosomes. Additionally, these authors recorded dark $\mathrm{C}$-bands in the telomeric regions of two pairs of subtelocentric or submetacentric autosomes. This C-banding pattern is thus different from that observed in our study in both $N$. xanthodon and $N$. ehrenbergi populations where the amount of pericentromeric $\mathrm{C}$-heterochromatin was very low in the acrocentric autosomes and the telomeric positive $\mathrm{C}$-bands were absent. Contrary to previous findings in other cytotypes (Ivanitskaya et al. 1997, Arslan et al. 2011a, Arslan et al. 2013), we have not recorded any C-heterochromatic short arms in the complements under study.
The pattern of the NORs distribution is rather uniform among populations of mole rats with varying chromosomal numbers. The number of the NOR-bearing autosomal pairs varies from two to five; however, their actual localization may involve various autosomal pairs (Ivanitskaya et al. 1997, 2008, Arslan et al. 2011a, 2013, 2014). Gülkaç and Küçükdumlu (1999) localized NORs in two pairs of subtelocentric autosomes in the $2 n=52$ complement. Ivanitskaya et al. (1997) recorded NORs in the two largest subtelocentric pairs and, additionally, also in the small submetacentric pair possessing the telomeric dark C-band. In the Iraqi population with 52 chromosomes, Coşkun et al. (2014) localized NORs in three autosomal pairs, including a large and a small submetacentric pair, and the smallest acrocentric pair.

It is difficult to find particular chromosomal differences enabling the distinction between $N$. xanthodon and N. ehrenbergi. The studied populations differed in the proportion of bi-armed and uni-armed autosomes and in the number and distribution of NORs. In the population recognized as $N$. ehrenbergi, the number of detected NORs was five, and a site was localized in an acrocentric autosome. However, it is questionable if such variation could be used as a species-specific character for reliable species identification. The proportion of the 
bi-armed and acrocentric autosomes commonly varies between populations of mole rats with the same diploid number of chromosomes (Arslan et al. 2013, 2014) and such variation was reported also in the 52 chromosome race. The previously published karyological data on the 52 chromosome cytotype showed considerable variation also in the C-banding and AgNOR staining pattern, and this variability makes the search for species-specific cytogenetic characters difficult.

\section{Conclusions}

We can conclude that the populations of blind mole rats from Anatolia in Turkey classified as $N$. xanthodon and $N$. ehrenbergi reveal little difference in their karyotype structure, and hardly, any species distinguishing character can be defined based on the comparison of their chromosomal complements. This finding emphasizes the need of taxonomic revision of the species status and composition within the Nannospalax genus and cytogenetic studies using structural chromosome banding techniques will certainly be useful in this respect. The use of sensitive molecular markers such as microsatellites is obviously desirable to estimate the extent of gene flow and possible reproductive isolation between populations.

\section{Competing interests}

The authors declare that they have no competing interests.

\section{Authors' contributions}

AA collected the studied specimen, performed the cytogenetic analysis, designed the study, and contributed to interpretation of results. JZ contributed to the cytogenetic analysis and the arrangement of the karyotypes obtained, contributed to analysis and interpretation of results, and wrote the manuscript. Both authors read and approved the final manuscript.

\section{Acknowledgements}

This study was supported by grants from the Coordination Committee of Scientific Research Projects of Selçuk University (BAP, no. 14401098).

\section{Author details}

${ }^{1}$ Department of Biology, Faculty of Science, Selçuk University, 42031 Konya, TR, Turkey. ${ }^{2}$ Institute of Vertebrate Biology, Academy of Sciences of the Czech Republic, Kvetna 8, 60365 Brno, CZ, Czech Republic.

Received: 24 July 2014 Accepted: 16 December 2014

Published online: 09 January 2015

\section{References}

Arslan A (2013) A new live trap to catch blind mole rats (Spalax sp.). Folia Zool 62:130-132

Arslan A, Akan \$̧, Zima J (2011a) Variation in C-heterochromatin and NORs distribution among chromosomal races of mole rats (Spalacidae) from Central Anatolia, Turkey. Mamm Biol 76:28-35

Arslan A, Arisoy A, Zima J (2013) The chromosome banding pattern in two cytotypes ( $2 n=36$ and 38 ) of blind mole rats from Turkey (Mammalia: Spalacidae). Zool Middle East 59:95-100

Arslan A, Arısoy A, Zima J (2014) Comparison of the chromosome banding pattern in the $2 n=56$ cytotypes of Nannospalax leucodon and N. xanthodon from Turkey. Scientific World Journal 2014:121690, doi:10.1155/2014/121690

Arslan A, Bölükbaş F (2010) C-heterochromatin and NORs distribution of mole rat, Nannospalax xanthodon from Aksaray, Turkey. Caryologia 63:398-404
Arslan A, Toyran K, Gözütok S, Yorulmaz T (2011b) C- and NOR stained karyotypes of mole rat, Nannospalax xanthodon $(2 n=54)$ from Kırıkkale, Turkey. Turk J Biol 35:655-661

Arslan A, Zima J (2013) The banded karyotype of the $2 n=58$ chromosomal race of mole rat from Erzincan, Turkey. Folia Zool 62:19-23

Arslan A, Zima J (2014) Karyotypes of the mammals of Turkey and neighbouring regions: a review. Folia Zool 63:1-62

Bukhnikashvili A, Kryštufek B, Sozen M, Yigit N, Amori G (2008) Spalax nehringi. The IUCN Red List of Threatened Species. Version 2014.1. [www.iucnredlist.org] Downloaded on 17 July 2014

Chişamera G, Bužan EV, Sahlean T, Murariu D, Zupan S, Kryštufek B (2014) Bukovina blind mole rat Spalax graecus revisited: phylogenetics, morphology, taxonomy, habitat associations and conservation. Mamm Rev 44:19-29

Coşkun Y (2004) A new species of mole rat, Nannospalax munzuri sp. n., and karyotype of Nannospalax tuncelicus (Coşkun, 1996) (Rodentia: Spalacidae) in eastern Anatolia. Zool Middle East 33:153-162

Coşkun Y, Aşan Baydemir NA, Kaya A, Karöz AM (2014) Nucleolar organizer region distribution in Nannospalax ehrenbergi (Nehring, 1898) (Rodentia: Spalacidae) from Iraq. Turk J Zool 38:250-253

Coșkun Y, El Namee A, Kaya A (2012) Karyotype of Nannospalax ehrenbergi (Nehring, 1898) (Rodentia, Spalacidae) in the Mosul Province, Iraq. Hystrix It J Mamm (ns) 23:75-78

Coşkun Y, Ulutürk S, Kaya A (2010) Karyotypes of Nannospalax (Palmer 1903) populations (Rodentia: Spalacidae) from central-eastern Anatolia, Turkey. Hystrix It J Mamm (ns) 21:89-96

Coșkun Y, Ulutürk S, Yürümez G (2006) Chromosomal diversity in mole-rats of the species Nannospalax ehrenbergi (Mammalia: Rodentia) from South Anatolia, Turkey. Mamm Biol 71:244-250

Ford CE, Hamerton JL (1956) A colchicine, hypotonic citrate, squash sequence for mammalian chromosomes. Stain Technol 31:247-251

Gülkaç MD, Küçükdumlu I (1999) Variation in the nucleolus organizer regions (NORs) in two mole rat species (Spalax leucodon and Spalax ehrenbergi). Turk J Biol 23:153-158

Howell WM, Black DA (1980) Controlled silver staining of nucleolar organizer regions with a protective colloidal developer: a 1-step method. Experientia 36:1014-1015

Hsu TC, Benirschke K (1967-1977) An atlas of mammalian chromosomes, vol 1-10. Springer Verlag, Berlin-Heidelberg-New York

Ivanitskaya E, Coskun Y, Nevo E (1997) Banded karyotypes of mole rats (Spalax, Spalacidae, Rodentia) from Turkey: a comparative analysis. J Zool Syst Evol Res 35:171-177

Ivanitskaya E, Sözen M, Rashkovetsky L, Matur F, Nevo E (2008) Discrimination of $2 n=60$ Spalax leucodon cytotypes (Spalacidae, Rodentia) in Turkey by means of classical and molecular cytogenetic techniques. Cytogenet Genome Res 122:139-149

Kankılıç T, Gürpinar C (2014) Revised classification design of the Anatolian species of Nannospalax (Rodentia: Spalacidae) using RFLP analysis. Turk J Zool 38:68-78

Kryštufek B, Vohralík V (2009) Mammals of Turkey and Cyprus. Rodentia II: Cricetinae, Muridae, Spalacidae, Calomyscidae, Hystricidae, Castoridae. Univerzita za Primorskem, Koper

Musser G, Carleton M (2005) Superfamily Muroidea. In: Wilson DE, Reeder DM (eds) Mammal species of the world. A taxonomic and geographic reference, 2nd edn. The Johns Hopkins University Press, Baltimore, pp 894-1531

Nevo E, Filippucci MG, Redi C, Simson S, Heth G, Beiles A (1995) Karyotype and genetic evolution in speciation of subterranean mole rats of the genus Spalax in Turkey. Biol J Linn Soc 54:203-229

Nevo E, Ivanitskaya E, Beiles A (2001) Adaptive Radiation of blind subterranean mole rats: naming and revisiting the four sibling species of the Spalax ehrenbergi superspecies in Israel: Spalax galili $(2 n=52)$, S. golani $(2 n=54)$, S. carmeli $(2 \mathrm{n}=58)$ and S. judaei $(2 \mathrm{n}=60)$. Backhuys Publishers, Leiden

Schlitter D, Shenbrot G, Kryštufek B, Sozen M (2008) Spalax ehrenbergi. The IUCN Red List of Threatened Species. Version 2014.1. [www.iucnredlist.org] Downloaded on 17 July 2014

Sözen M (2004) A karyological study on subterranean mole rats of the Spalax leucodon Nordmann, 1840 superspecies in Turkey. Mamm Biol 64:420-429

Sözen M, Çolak F, Sevindik M, Matur F (2013) Cytotypes of Nannospalax xanthodon (Satunin, 1898) (Rodentia, Spalacidae) from western Anatolia. Turk J Zool 37:462-469 
Sözen M, KIvanç E (1998) Two new karyotypic forms of Spalax leucodon Nordmann, 1840 (Mammalia: Rodentia) from Turkey. Z Säugetierkunde 63:307-310

Sumner AT (1972) A simple technique for demonstrating centromeric heterochromatin. Exp Cell Res 75:304-306

Yüksel E (1984) Cytogenetic study in Spalax (Rodentia: Spalacidae) from Turkey. Comm Fac Sci Univ Ankara Serie 2:1-11

Submit your manuscript to a SpringerOpen ${ }^{\circ}$ journal and benefit from:

- Convenient online submission

- Rigorous peer review

- Immediate publication on acceptance

- Open access: articles freely available online

- High visibility within the field

- Retaining the copyright to your article

Submit your next manuscript at $>$ springeropen.com 